\title{
Effects of paracrine factors on CD24 expression and neural differentiation of male germline stem cells
}

\author{
BANG-JIN KIM ${ }^{1}$, YONG-AN LEE ${ }^{1,4}$, KI-JUNG KIM ${ }^{1}$, YONG-HEE KIM ${ }^{1}$, \\ MI-SEON JUNG ${ }^{1}$, SEUNG-JUNG HA ${ }^{1}$, HYUN-GU KANG ${ }^{1}$, SANG-EUN JUNG ${ }^{1}$, BYUNG-GAK KIM ${ }^{3}$, \\ $\mathrm{YU}_{-\mathrm{RI}} \mathrm{CHOI}^{1}$, JEONG TAE DO ${ }^{2}$ and BUOM-YONG RYU ${ }^{1}$ \\ ${ }^{1}$ Department of Animal Science and Technology, Chung-Ang University, Anseong; ${ }^{2}$ Department of Animal Biotechnology, \\ College of Animal Bioscience and Technology, Konkuk University, Seoul, Republic of Korea; \\ ${ }^{3}$ Department of Obstetrics, Gynecology and Reproductive Biology, Michigan State University, East Lansing, MI, USA
}

Received January 12,2015; Accepted April 27, 2015

DOI: $10.3892 /$ ijmm.2015.2208

\begin{abstract}
Spermatogonial stem cells (SSCs) are adult male germ cells that develop after birth. Throughout the lifetime of an organism, SSCs sustain spermatogenesis through selfrenewal and produce daughter cells that differentiate into spermatozoa. Several studies have demonstrated that SSCs can acquire pluripotency under appropriate culture conditions, thus becoming multipotent germline stem cells (mGSCs) that express markers of pluripotency in culture and form teratomas following transplantation into immunodeficient mice. In the present study, we generated neural precursor cells expressing CD24, a neural precursor marker, from pluripotent stem cell lines and demonstrated that these cells effectively differentiated along a neural lineage in vitro. In addition, we found that paracrine factors promoted CD24 expression during the neural differentiation of mGSCs. Our results indicated that the expression of CD24, enhanced by a combination of retinoic acid (RA), noggin and fibroblast growth factor 8 (FGF8) under serum-free conditions promoted neural precursor differentiation. Using a simple cell sorting method, we were able to collect neural precursor cells with the potential to differentiate from mGSCs into mature neurons and astrocytes in vitro.
\end{abstract}

\section{Introduction}

Embryonic stem cells (ESCs) have the ability to differentiate into functional neurons and glia through a mechanism akin

Correspondence to: Professor Buom-Yong Ryu, Department of Animal Science and Technology, Chung-Ang University, 4726 Seodongdaero, Daedeok-myeon, Anseong-si, Gyeonggi-do 456-756, Republic of Korea

E-mail: byryu@cau.ac.kr

Present address: ${ }^{4}$ Department of Chemistry, National University of Singapore, 11 Biopolis Way, \#02-02 Helios, Singapore 138667, Singapore

Key words: multipotent germline stem cells, pluripotency, CD24, neural differentiation, retinoic acid to in vivo development (1-6). However, several issues, such as ethical concerns and the immune rejection of allograft transplants, impede the use of ESCs.

A major advance in stem cell biology has been the direct reprogramming of somatic cells through the induction of transcription factor expression to produce induced pluripotent stem cells (iPSCs) $(7,8)$. This technique has attracted considerable attention worldwide due to its applications in human disease modeling, drug screening and translational medicine $(7,8)$. iPSCs derived from adult somatic cells can differentiate into various cell types, including cells of the three embryonic germ layers. This finding facilitates in vitro studies on neuronal disorders by enabling the generation of neural lineage cells, such as oligodendrocytes, astrocytes and neurons. However, iPSC-based applications are limited by safety concerns and their complexity, as the generation of iPSCs typically involves the integration of exogenous transcription factor-encoding genes (8).

Spermatogonial stem cells (SSCs) are adult male germ cells that develop after birth and serve as a reservoir of cells that can differentiate into spermatozoa throughout the lifetime of an organism (9). Several studies have demonstrated that SSCs can acquire pluripotency under appropriate culture conditions (10-16). Such multipotent germline stem cells (mGSCs) express markers of pluripotency in culture and produce teratomas when transplanted into immunodeficient mice. These cells can differentiate into cell types derived from all three embryonic germ layers (10-16). We recently reported that mGSCs derived from adult mouse testis are pluripotent and can differentiate similarly to ESCs and iPSCs (17). These data demonstrate that the male GSC lineage can be altered in vitro and that unipotent cells can become pluripotent without the addition of exogenous transcription factors. mGSCs can be used without ethical and immunological concerns in personalized cell-based therapies for patients. In addition, Glaser et al demonstrated that mGSCs develop into functional neurons with active functional networks and engage in synchronized oscillatory activity (18).

Fluorescence-activated cell sorting (FACS) is used to sort cellular populations based on fluorescent labeling $(19,20)$. A neuronal lineage marker profile is required, similar to the lineage specification profile of cluster of differentiation (CD) 
antigens used for hematopoiesis $(21,22)$. For translational stem cell research, we hypothesized that a neuronal precursor cell separation methodology based on a neuronal lineage marker profile would enable the efficient transplantation of viable neural stem cell populations.

In the present study, we generated neural precursor cells expressing CD24, a neural precursor marker, from pluripotent stem cell (PSC) lines and demonstrated that these cells effectively differentiated along the neural lineage in vitro. Using mGSCs, we also investigated the effects of paracrine molecules on $\mathrm{CD} 24$ expression during neural lineage differentiation.

\section{Materials and methods}

All procedures were performed according to the guidelines for the ethical treatment of animals and were approved by the Institutional Animal Care and Use Committee of Chung-Ang University, Seoul, Korea.

Cell culture and differentiation. Unless otherwise stated, all reagents were purchased from Sigma-Aldrich (St. Louis, MO, USA). The mGSCs were cultured according to the method described in our previous study [Kim et al (17)]. Testicular cells were collected from the testes of adult (6-week-old) POU class 5 homeobox 1 (Pou5f1)-green fluorescent protein $(G F P)$ transgenic mice [B6; CBA-Tg (Pou5fl-EGFP) 2Mnn/J; Jackson Laboratory, Bar Harbor, ME, USA] using a two-step enzymatic digestion procedure. Following enzymatic digestion, $1 \times 10^{7}$ testicular cells were plated onto 100 -mm culture dishes coated with $0.1 \%(\mathrm{w} / \mathrm{v})$ gelatin and cultured in GSC culture medium. After 7 days of continuous culture, GSC clumps were collected by gentle pipetting. The harvested GSCs were cultured on a monolayer of mitomycin C-inactivated mouse embryonic fibroblasts (MEFs) in a 24-well culture dish and passaged once every 7 days at a dilution of $1: 2$ to $1: 3$. The expression of Pou5fI-GFP was monitored, and morphologically atypical transitional colonies were mechanically selected. To convert the GSCs into mGSCs, the colonies were replated onto MEFs in standard ESC medium [Dulbecco's modified Eagle's medium (DMEM; Invitrogen, Grand Island, NY, USA) supplemented with $15 \%$ fetal bovine serum (FBS; HyClone/Thermo Scientific, Logan, UT, USA), $1 \%$ minimal essential medium non-essential amino acids (Invitrogen), $2 \mathrm{mM} \mathrm{L}$-glutamine (Invitrogen), penicillin/streptomycin (penicillin, 50 units $/ \mathrm{ml}$; streptomycin, $50 \mu \mathrm{g} / \mathrm{ml}$; Invitrogen), $50 \mu \mathrm{M} \beta$-mercaptoethanol and $103 \mathrm{U} / \mathrm{ml}$ leukemia inhibitory factor (Thermo Scientific)]. Neural stem cells (NSCs)-iPSCs were cultured according to the method described in the study by Do et al (46). Briefly, embryos were extracted from parthenogenetic pregnant female mice at 10.5 days post-coitum and brain tissue was collected from the embryos $\left(\mathrm{OG}^{++-}\right)$for the generation of NSCs. To induce the expression of Pouff1, SRY (sex determining region Y)-box 2 (Sox2), Krüppel-like factor 4 (KLf4) and c-Myc, the NSCs were transduced with retrovirus-containing supernatants for $24 \mathrm{~h}$. The cells were replated onto MEF feeders in ESC medium. The Pou5f1-GFP ${ }^{+}$iPSCs were sorted with FACS and subcultured onto MEF feeders. Prior to differentiation, the PSCs were plated onto gelatin-coated dishes with ESC medium for $40 \mathrm{~min}$ to remove the feeder cells. For differentiation, the PSCs were cultivated as embryoid bodies (EBs) using different media. The cells were transferred to 24-well ultra-low attachment plates (Corning, Midland, MI, USA) and cultured at $4 \times 10^{4}$ cells $/ \mathrm{ml} /$ well in standard ESC medium, NeuroCult (NeuroCult basal medium with 1X NeuroCult NSC proliferation supplements; StemCell Technology, Vancouver, BC, Canada), or N2/B27 medium [DMEM-F12 (Invitrogen) supplemented with 1\% B27 (Invitrogen), $0.5 \% \mathrm{~N} 2$ (Invitrogen), $100 \mu \mathrm{M} \beta$-mercaptoethanol and $2 \mathrm{mM} \mathrm{L}$-glutamine]. The cells were seeded in the presence of either growth factors or inhibitors, as indicated.

Reverse-transcription-quantitative PCR. Total RNA was isolated from the cells using a PureLink RNA Mini kit (from Invitrogen) and reverse transcribed using SuperScript III reverse transcriptase (Invitrogen), according to the manufacturer's instructions. Quantitative PCR (qPCR) was performed using the SYBR-Green PCR Mix (from Applied Biosystems, Grand Island, NY, USA) and a 7500 Real-Time PCR system (Applied Biosystems). All gene expression levels were determined by RT-qPCR and normalized to the level of glyceraldehyde 3-phosphate dehydrogenase $(G A P D H)$. The primers used were as follows: nestin forward, 5'-AGTTTGGT CGTGGGGAGATT-3' and reverse, 5'-ACTTTGGGGAGG CAGGAG-3'; tyrosine hydroxylase (TH) forward, 5'-TTGAA GCCAAAATCCACCA-3' and reverse, 5'-AGACACCCGACG CACAG-3'; microtubule-associated protein $(M A P) 2$ forward, 5'-GGGCACCTATTCAGATACCAAA-3' and reverse, 5'-TCC TTCTCTTGTTCACCTTTCAG-3'; $M b p$ forward, 5'-GCT TCTTTAGCGGTGACAGG-3' and reverse, 5'-TGTGTGAGTC CTTGCCAGAG-3'; Tubb3 forward, 5'-GAATGACCTGGTG TCCGAGT-3' and reverse, 5'-CCGATTCCTCGTCATC ATCT-3'; and GAPDH forward, 5'-CCACTCACGGCAAAT TCA-3' and reverse, 5'-GACTCCACGACATACTCAGCAC-3'.

Flow cytometry and cell sorting. EBs generated from the differentiation experiments with the PSCs were dissociated by incubating the cells with trypsin-EDTA (Invitrogen). The cells were stained for specific markers using the following antibodies: anti-mouse CD24-allophycocyanin (APC; Cat. no. 17-0242) and IgG2a isotype control-APC (Cat. no. 17-4210; eBioscience, San Diego, CA, USA). The dissociated cells were suspended in Dulbecco's phosphate-buffered saline (PBS; Invitrogen) supplemented with $1 \%$ FBS, $10 \mathrm{mM}$ HEPES, $1 \mathrm{mM}$ pyruvate, $50 \mathrm{U} /$ $\mathrm{ml}$ penicillin (Invitrogen), $50 \mu \mathrm{g} / \mathrm{ml}$ streptomycin (Invitrogen) and $1 \mathrm{mg} / \mathrm{ml}$ glucose (PBS-S). The cells were incubated with the appropriate antibodies for $20 \mathrm{~min}$ on ice, washed twice with excess PBS-S and used for FACS analysis. After the final wash, the cells were resuspended $\left(1 \times 10^{6}\right.$ cells $\left./ \mathrm{ml}\right)$ in PBS-S containing $1 \mu \mathrm{g} / \mathrm{ml}$ propidium iodide (PI) and kept on ice in the dark until analysis. Flow cytometric analyses and cell sorting were performed using a dual-laser FACS Aria II (BD Biosciences, San Jose, CA, USA) at the Center for Research Facilities, Chung-Ang University, Korea. The isotype control was used to define the gate in all FACS analyses. The sorted cells were centrifuged and plated onto $0.1 \%$ gelatin-coated coverslips in $\mathrm{N} 2 / \mathrm{B} 27$ medium containing $10 \mathrm{ng} / \mathrm{ml}$ basic fibroblast growth factor (bFGF; BD Biosciences) and $5 \mathrm{nM}$ retinoic acid (RA).

To evaluate the effect of additional growth factors on neural differentiation, RA (Cat. no. R2625; Sigma), bone morphogenetic protein 4 (BMP4, Cat. no. 4050-BP; R\&D Systems, Minneapolis, MN, USA), Noggin (Cat. no. 719-NG; 

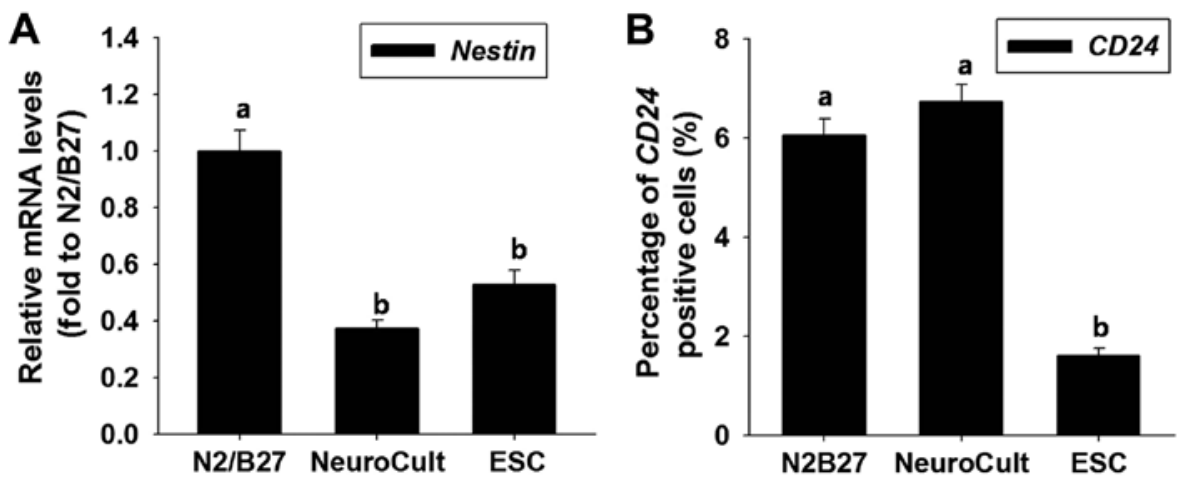

Figure 1. Effect of the differentiation medium on neural stem/precursor markers. (A) RT-qPCR of nestin expression in differentiated multipotent germline stem cells (mGSCs) cultured in N2/B27, NeuroCult or standard ESC medium. The expression levels were assessed after 2 days in suspension culture. (B) CD24 expression in cells cultured in different neural differentiation media was analyzed with flow cytometry 3 days after differentiation (data are the means \pm SEM; $\mathrm{n}=3$ ). Mean values labeled with different letters indicate significant differences $(\mathrm{P}<0.05)$. ESC, standard embryonic stem cell medium.

R\&D Systems), Sonic hedgehog (Shh, Cat. no. 461-SH-025; R\&D Systems), glial cell line-derived neurotrophic factor (GDNF, Cat. no. 212-GD; R\&D Systems), fibroblast growth factor 8 (FGF8, Cat. no. 110-25; Peprotech, Rocky Hill, NJ, USA), and bFGF (Cat. no. 354060; BD Biosciences) were added during differentiation. Dimethyl sulfoxide (DMSO, Cat. no. D2650; Sigma) was also used as a solvent for RA.

Immunocytochemical staining. For immunocytochemical staining, the cells were fixed with $4 \%$ paraformaldehyde for $30 \mathrm{~min}$ at room temperature, permeabilized with $0.1 \%$ Triton X-100 (Sigma) for $15 \mathrm{~min}$, and incubated with 5\% (w/v) bovine serum albumin (BSA; Roche, Basel, Switzerland) at room temperature for $30 \mathrm{~min}$. The cells were then incubated with a primary antibody against MAP2 (Cat. no. sc-32791; Santa Cruz Biotechnology, Dallas, TX, USA), TH (Cat. no. sc-14007; Santa Cruz Biotechnology), or glial fibrillary acidic protein (GFAP; Cat. no. sc-33673; Santa Cruz Biotechnology) diluted 1:200 in 5\% BSA solution and incubated overnight at $4^{\circ} \mathrm{C}$. Following 2 washes with PBS, the cells were incubated with the respective secondary antibodies: Alexa Fluor 488 goat antimouse (Cat. no. A11001; Invitrogen) for GFAP and Alexa Fluor 488 donkey anti-rabbit (Cat. no. A21206; Invitrogen) for $\mathrm{TH}$. The secondary antibodies were diluted 1:200 in 5\% BSA and incubated for $1 \mathrm{~h}$ at room temperature in the dark. The cells were then washed twice with PBS and mounted on glass slides using Vectashield containing 4',6-diamidino-2-phenylindole (DAPI) (Vector Laboratories, Burlingame, CA, USA). The slides were viewed using a Nikon TE 2000-U fluorescence microscope (Nikon, Tokyo, Japan).

Statistical analysis. Statistical analysis was conducted using SPSS version 18 software (SPSS Inc., Mechanicsburg, PA, USA). Significant differences between mean values were assessed using Tukey's honestly significant difference test and an independent $t$-test. Differences were considered statistically significant at $\mathrm{P}<0.05$.

\section{Results}

Effects of medium on the neural differentiation of mGSCs. To assess the effects of the different media on the differentiation of the mGSCs, EBs were generated and cultured for 2 days in N2/B27, NeuroCult, or standard ESC medium in the absence of any factors, as previously described (17). Nestin is an intermediate filament-related protein, which has to date been found only in vertebrates. It is widely accepted as an NSC marker, both during embryonic development and in the brain at later stages of development $(2,3)$. In this study, we examined the temporal gene expression pattern of nestin, using RT-qPCR to determine the level of nestin required to induce the differentiation of the cells into the neural lineage. The RT-qPCR data demonstrated a significant upregulation of nestin mRNA expression during neural differentiation in N2/B27 medium (Fig. 1A).

EBs produced in the different media were harvested 3 days after they were formed. The cells were dissociated with enzymatic digestion and analyzed by flow cytometry. CD24 was used as a marker of neural precursor populations and was found to be expressed in $6.1 \pm 0.3,6.7 \pm 0.4$ and $1.6 \pm 0.2 \%$ of the EBs following culture in N2/B27, NeuroCult and standard ESC medium, respectively. Thus, $\mathrm{CD} 24$ was expressed at low levels when the EBs were formed in ESC medium (Fig. 1B). On the basis of nestin and CD24 expression, subsequent experiments were performed using N2/B27 medium for neural differentiation.

Evaluation of the neural differentiation potential of sorted $\mathrm{CD} 24^{+}$cells. The functions of dopaminergic neurons and the neurotransmitter, dopamine, have been extenstively investigated [reviewed in (23)]. TH has been widely used as a marker of dopaminergic neurons as it is the first enzyme in the dopamine synthesis pathway, as well as the rate-limiting enzyme in dopamine synthesis. Microtubule assembly dynamics are regulated by proteins known as MAPs, including MAP1, MAP2 and Tau, which are expressed primarily in neurons. Among the neuronal MAPs, MAP2 expression is considered a marker of neural differentiation $(24,25)$. MAP2, found primarily in the dendritic extensions of post-mitotic, terminally differentiated neurons, plays a role in neurite outgrowth and dendrite induction (26-28).

mESCs, iPSCs and mGSCs were cultured in the indicated differentiation medium for 3 days to generate EBs, which were then dissociated and sorted into $\mathrm{CD} 24^{+}$and $\mathrm{CD} 24$ cells. We evaluated the differentiation potential of these cells follwoing further differentiation in a monolayer culture. On day 3 following differentiation, the cells were stained with 

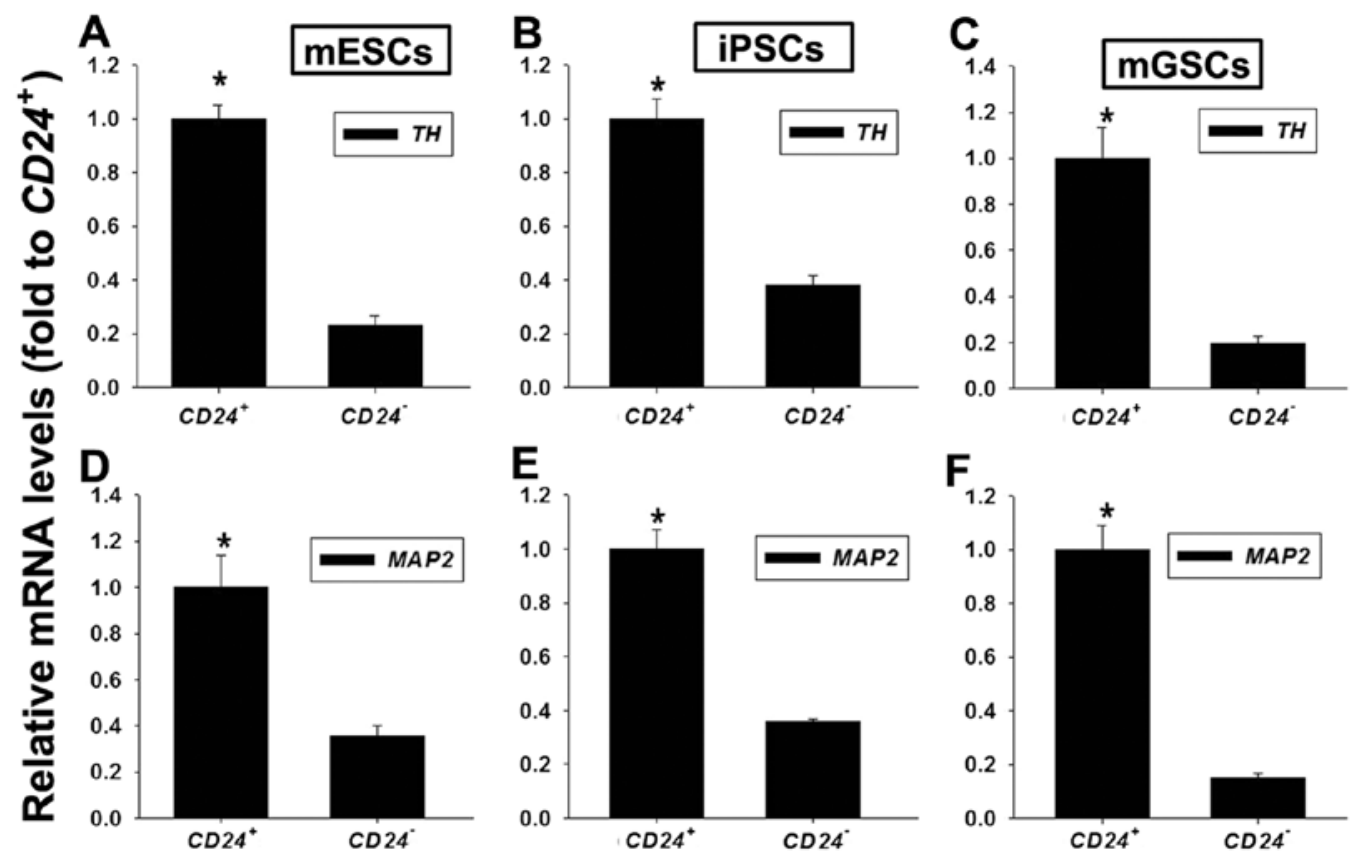

Figure 2. Comparison of the relative expression of neuron-specific genes in CD24+- and CD24--derived cells. Expression of the neural cell marker genes, tyrosine hydroxylase (TH) and microtubule-associated protein 2 (MAP2), after 10 days of differentiation. Multipotent germline stem cells (mGSCs) were cultured in N2/ B27 medium for 3 days to generate embryoid bodies (EBs), which were then dissociated and sorted by FACS into CD24 and CD24- cells using a CD24 antibody. The cells were plated separately on $0.1 \%$ gelatin-coated plates and cultured for an additional 7 days (data are the means \pm SEM; $n=3$ ). Mean values labeled with different letters indicate significant differences $(\mathrm{p}<0.05)$.

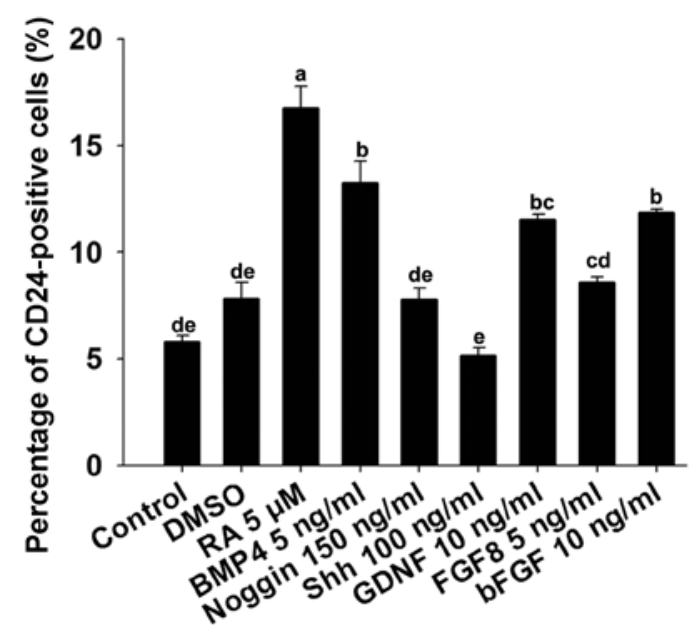

Figure 3. Effect of paracrine molecules on CD24 expression in multipotent germline stem cell (mGSC)-derived cells. mGSCs were induced to differentiate with the indicated concentrations of paracrine factors in suspension culture for 3 days, and FACS analysis was performed with the mGSC-derived cells using a CD24 antibody (data are the means \pm SEM; $n=3$ ). Mean values labeled with different letters indicate significant differences $(\mathrm{P}<0.05)$. DMSO, dimethyl sulfoxide; RA, retinoic acid; BMP4, bone morphogenetic protein 4 Shh, sonic hedgehog; GDNF, glial cell line-derived neurotrophic factor; FGF8, fibroblast growth factor 8; bFGF, basic fibroblast growth factor.

an APC-conjugated CD24 antibody, and the sorted cells were plated onto $0.1 \%$ gelatin-coated 24-well plates in N2/ B27 medium containing $10 \mathrm{ng} / \mathrm{ml}$ of bFGF and $5 \mathrm{nM}$ of RA. After 7 days, mRNA was isolated from these cultures, and RT-qPCR was performed to assess the TH and MAP2 expression levels. TH expression in the $\mathrm{CD} 24^{+}$cells was upregulated when compared with its expression in CD24- cells (4.3-,
2.6- and 5-fold higher in $\mathrm{CD} 24^{+}$cells vs. $\mathrm{CD} 24^{-}$cells derived from mESCs, iPSCs and mGSCs, respectively) (Fig. 2A-C). Additionally, MAP2 expression was higher in the $\mathrm{CD} 24^{+}$cells than in the CD24- cells (2.9-, 2.8- and 6.7-fold higher in the $\mathrm{CD} 24^{+}$cells vs. the CD24- cells derived from mESCs, iPSCs and mGSCs, respectively) (Fig. 2D-F).

Effect of paracrine factors on $\mathrm{CD} 24^{+}$neural precursor induction. In order to determine whether paracrine factors induce the specific differentiation of mGSCs into CD24-expressing neural precursor cells, the mGSCs were treated with $100 \mathrm{ng} / \mathrm{ml} \mathrm{Shh}$, $5 \mu \mathrm{M}$ RA, $150 \mathrm{ng} / \mathrm{ml}$ noggin, $5 \mathrm{ng} / \mathrm{ml} \mathrm{FGF8}, 10 \mathrm{ng} / \mathrm{ml} \mathrm{bFGF}$, $10 \mathrm{ng} / \mathrm{ml}$ GDNF or $5 \mathrm{ng} / \mathrm{ml}$ BMP 4 . DMSO $(1 \mu \mathrm{l} / \mathrm{ml})$ in N2/ B27 medium was used as a solvent control. The FACS data demonstrated that the percentage of cells expressing CD24 was higher in the RA-treated group than in the other groups (control, $5.8 \pm 0.3 \%$; DMSO, $7.8 \pm 0.7 \%$; RA, $16.8 \pm 1.0 \%$; BMP4, $13.3 \pm 1.0 \%$; noggin, $7.8 \pm 0.5 \%$; Shh, $5.2 \pm 0.4 \%$; GDNF, $11.5 \pm 0.2 \%$; FGF8, 8.6 $\pm 0.3 \%$; bFGF, $11.9 \pm 0.1 \%$; mean \pm SEM; $n=3$ ) (Fig. 3).

To evaluate the optimal concentration of RA required for CD24 expression, 5, 50 and $500 \mathrm{nM}$, or $5 \mu \mathrm{M}$ of RA were added during neural differentiation. The percentage of cells expressing CD24 was $22.8 \pm 1.9,17.3 \pm 0.9,13.7 \pm 1.1$ and $14.7 \pm 1.5 \%$, respectively (mean \pm SEM; $n=3$ ) (Fig. 4). Thus, CD24 expression was higher in the group treated with $5 \mathrm{nM}$ RA than in the groups treated with $50 \mathrm{nM}, 500 \mathrm{nM}$ and $5 \mu \mathrm{M}$ RA. The increasing concentration of RA inhibited CD24 expression in the cells.

On the basis of these results, we used N2/B27 medium containing $5 \mathrm{nM} \mathrm{RA}$ as the basic condition for the neural differentiation of mGSCs. We then examined the effect of additional growth factors on CD24 expression. We added BMP4 $(5 \mathrm{ng} / \mathrm{ml})$, 


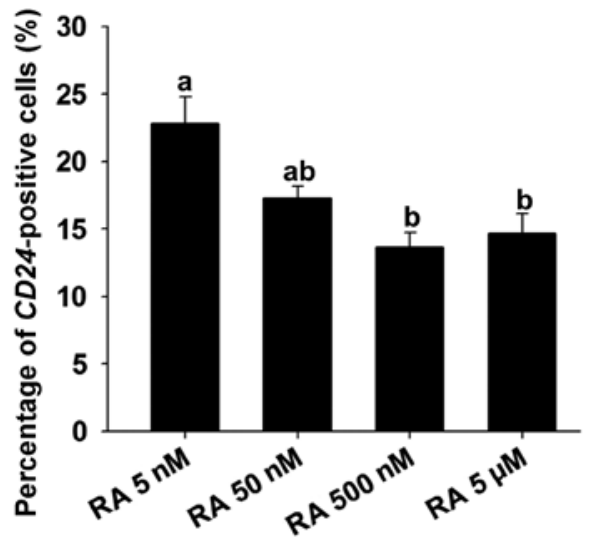

Figure 4. Effect of the retinoic acid (RA) concentration on the expression of CD24. Multipotent germline stem cells (mGSCs) were induced to differentiate with the indicated concentrations of RA in suspension culture for 3 days, and FACS analysis was performed with the mGSC-derived cells using a CD24 antibody (data are the means $\pm S E M ; n=3$ ). Mean values labeled with different letters indicate significant differences $(\mathrm{P}<0.05)$.

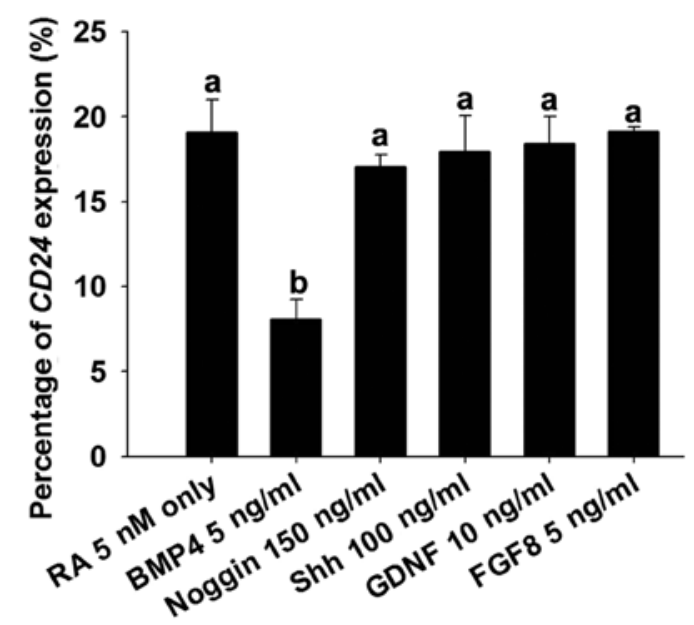

Figure 5. Effect of additional growth factors on the expression of CD24. Multipotent germline stem cells (mGSCs) were induced to differentiate with the indicated concentrations of additional growth factors in N2/B27 medium containing $5 \mathrm{nM}$ retinoic acid (RA) and maintained for 3 days. FACS analysis was performed with the mGSC-derived cells using a CD24 antibody (data are the means \pm SEM; $n=3$ ). Mean values labeled with different letters indicate significant differences $(\mathrm{P}<0.05)$. RA, retinoic acid; BMP4, bone morphogenetic protein 4; Shh, sonic hedgehog; GDNF, glial cell line-derived neurotrophic factor; FGF8, fibroblast growth factor 8 .

$\operatorname{noggin}(150 \mathrm{ng} / \mathrm{ml})$, Shh $(100 \mathrm{ng} / \mathrm{ml})$, GDNF $(10 \mathrm{ng} / \mathrm{ml})$, as well as FGF8 (5 ng/ml) and bFGF $(10 \mathrm{ng} / \mathrm{ml})$ to the $\mathrm{N} 2 / \mathrm{B} 27$ medium containing $5 \mathrm{nM}$ of RA. The percentage of CD24+ cells was $17.9 \pm 2.1,8.1 \pm 1.2,17.1 \pm 0.7,17.9 \pm 2.1,18.4 \pm 1.6$ and $19.1 \pm 0.3 \%$ in the groups of cells treated with $5 \mathrm{nM}$ RA alone or $5 \mathrm{nM}$ RA with BMP4, noggin, Shh, GDNF and FGF8/bFGF, respectively (mean \pm SEM; $n=3$ ) (Fig. 5). There were no significant differences observed between the groups, with the exception of the BMP4-treated group, in which the expression of CD24 was lower than that in the other groups (Fig. 5).

Effect of paracrine factors on neural lineage-specific marker expression. Class III $\beta$-tubulin (Tubb3), a microtubule protein, is selectively expressed in neural cells (29). Tubb3 antibodies

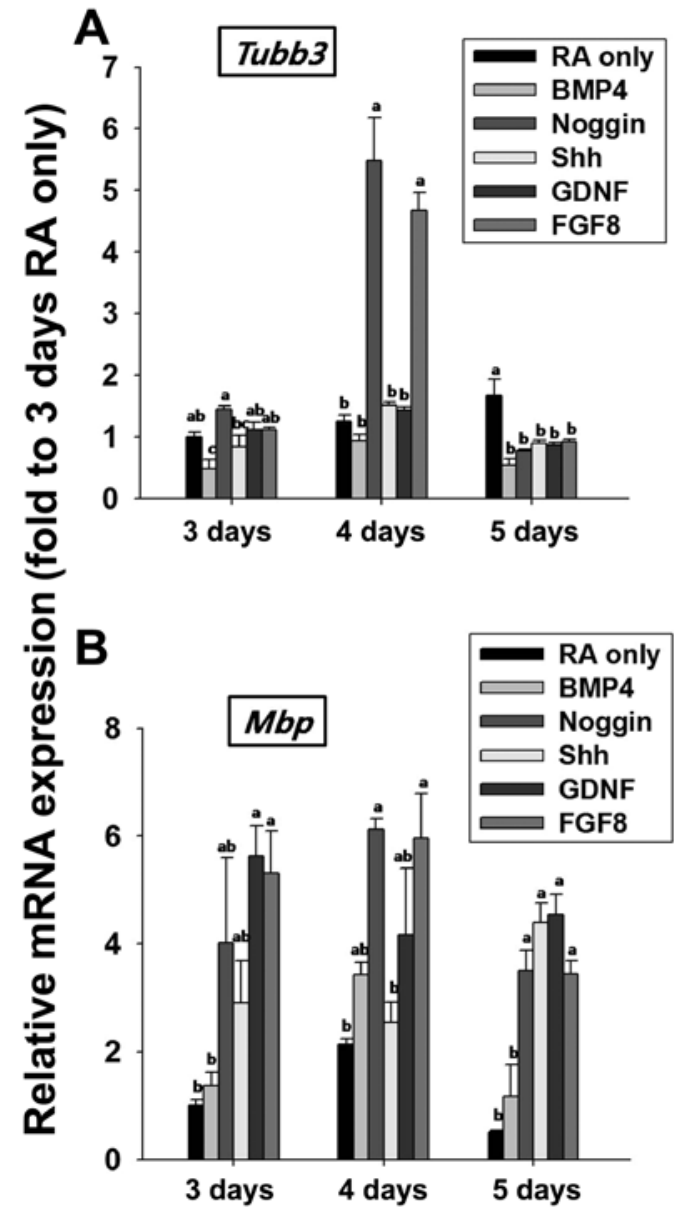

Figure 6. Comparison of the relative expression of neuron- and oligodendrocyte-specific markers. The differentiation of multipotent germline stem cells (mGSCs) was induced with BMP4 $(5 \mathrm{ng} / \mathrm{ml})$, noggin $(150 \mathrm{ng} /$ $\mathrm{ml})$, Shh (100 ng/ml), GDNF (10 ng/ml) and FGF8 (5 ng/ml) in N2/B27 medium containing $5 \mathrm{nM}$ RA. The culture was maintained for 3-5 days. (A) Class III $\beta$-tubulin (Tubb3) and (B) Myelin basic protein ( $M b p$ ) levels were normalized to those of neuronal- and oligodendrocyte-specific markers in cells cultured with RA alone 3 days following differentiation (data are the means \pm SEM; $n=3$ ). Mean values labeled with different letters indicate significant differences $(\mathrm{P}<0.05)$. RA, retinoic acid; BMP4, bone morphogenetic protein 4; Shh, sonic hedgehog; GDNF, glial cell line-derived neurotrophic factor; FGF8, fibroblast growth factor 8 .

and RT-qPCR-based gene expression studies have been used to identify cells of the neural lineage and to quantify neuronal cells during stem cell differentiation (29). Myelin basic protein (MBP) is an important factor in the nerve myelination process within the central nervous system (29) and is used as a marker of oligodendrocytes (30). In this study, to evaluate the effects of additional growth factors on mature cells of the neural lineage, BMP4 $(5 \mathrm{ng} / \mathrm{ml})$, noggin $(150 \mathrm{ng} / \mathrm{ml})$, Shh $(100 \mathrm{ng} / \mathrm{ml})$, GDNF $(10 \mathrm{ng} / \mathrm{ml})$ or FGF8 $(5 \mathrm{ng} / \mathrm{ml})$ were added to the N2/ B27 medium containing $5 \mathrm{nM}$ RA and the EBs were allowed to differentiate for 5 days. To determine the expression of neural $T u b b 3$ and $M b p$, the EBs were harvested at 3,4 and 5 days following differentiation, and RT-qPCR experiments were performed. We found that, 4 days after EB formation, Tubb3 expression was higher in the cells treated with noggin or FGF8 than in the cells treated with the other factors (Fig. 6A). Additionally, 4 days after neural induction, the expression of $M b p$ was higher in the cells treated with noggin or FGF8 than 

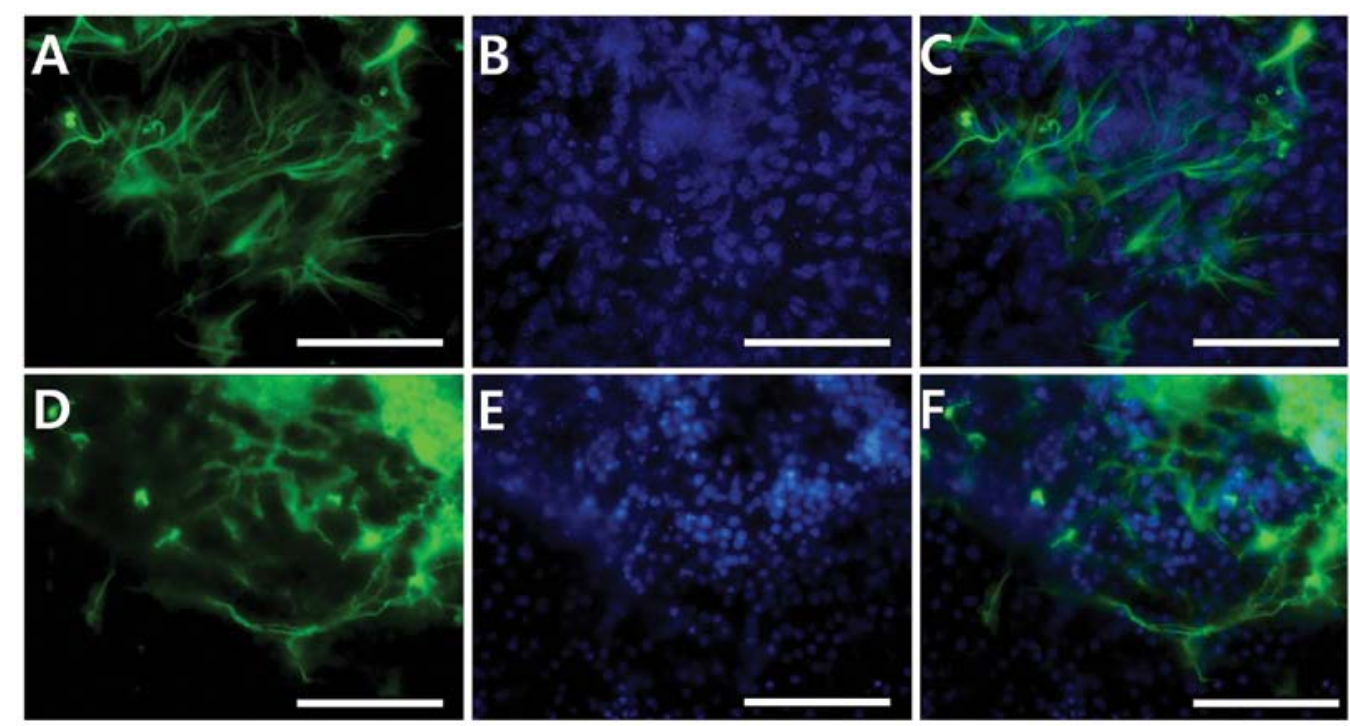

Figure 7. Expression of specific markers for multipotent germline stem cell (mGSC)-derived astrocytes and neurons. Immunocytochemical analysis was performed to detect the astrocyte marker, glial fibrillary acidic protein (GFAP), and the mature neuron marker, tyrosine hydroxylase (TH). (A) GFAP; (B) DAPI; (C) Merged image of panels A and B; (D) TH; (E) DAPI; (F) Merged image of panels D and E. Scale bars, $100 \mu \mathrm{m}$.

in the cells treated with RA alone or with Shh (Fig. 6B). These results indicate that noggin and FGF8 induce the differentiation of mGSCs into mature neural cells and that the expression of the neural markers, Tubb3 and Mbp, is maximal on day 4.

$\mathrm{CD} 24^{+}$cell populations induced with $\mathrm{RA}(5 \mathrm{nM})$, FGF8 (5 ng/ml) and Shh (100 ng/ml) were isolated through cell sorting on day 3 of differentiation. The cells were re-aggregated on V-shaped, ultra-low attachment 96-well plates at a density of $5 \times 10^{3}$ cells/well and incubated for 2 days. The re-aggregated EBs were transferred to a 96-well plate as a monolayer. After 5 days in a monolayer culture, the expression of TH and GFAP was analyzed. As shown in Fig. 7, CD24+ progenitor cellderived neural cells induced with a combination of paracrine factors expressed the mature neuron marker, $\mathrm{TH}$, and the astrocyte marker, GFAP.

\section{Discussion}

In the present study, we report that neuronal cells can be efficiently generated from a mouse mGSC line by combining a FACS-based system for the isolation of CD24-expressing neural precursors with paracrine factor treatment. Using this system, we generated PSC lines, assessed the expression of the neuron-specific genes, $T H$ and $M A P 2$, and demonstrated that $\mathrm{CD} 24^{+}$cells have greater potential than CD24- cells to differentiate into cells of the neural lineage.

The expression of nestin, a NSC marker, was upregulated when serum-free N2/B27 medium was used for differentiation (Fig. 1A). As serum contains several factors that may influence the differentiation process, a number of researchers have investigated the in vitro differentiation of ESCs into neurons or neural precursors using serum-free media (31-37). In addition, the serum-based protocols used to induce cell differentiation have been modified, with the goal of obtaining cells with specific neural phenotypes more efficiently (38-40). Several of these studies have used proprietary medium or serum, wherein it is difficult to identify the specific factors responsible for efficient ESC differentiation (41).

For translational approaches, it is best to purify transplanted cells, such as neural precursor cells, that have the capacity to differentiate into functional neurons. To this end, a transplantable cell candidate that can be efficiently purified needs to be identified. CD24 is a cell surface glycoprotein with numerous carbohydrate structures and a small protein core that attaches to the membrane through a glycosylphosphatidylinositol tail $(42,43)$. In the adult central nervous system, CD24 expression is restricted to immature neurons in two regions of the brain that exhibit ongoing neurogenesis, the subventricular zone of the lateral ventricle pathway and the dentate gyrus of the hippocampal formation. CD24 is also strongly expressed in ciliated ependymal cells (44). In the present study, FACSbased sorting of CD24-expressing cells revealed that the CD24 surface antigen defined subsets of cells differentiating along the neural precursor lineage. To investigate whether $\mathrm{CD} 24^{+}$cells undergo neurogenesis efficiently in vitro, we sorted CD24 and CD24- cells derived from mESCs, iPSCs and mGSCs on day 3 of differentiation and plated them for an additional 7 days in a monolayer culture. In the CD24+ cells derived from ESCs, iPSCs and mGSCs, the TH and MAP2 mRNA levels were upregulated to a similar extent relative to levels in CD24 cells (Fig. 2).

To induce the efficient differentiation of PSCs along a specific lineage, signaling pathways must be controlled by means of paracrine factors that regulate lineage-specific differentiation during embryonic development. Several factors that can promote the differentiation of PSCs into cells in the neural lineage have been identified (45-49). In the present study, the highest enrichment of the neuronal population was obtained with N2/B27 medium, regardless of exposure to RA, which is commonly used in vitro to induce the differentiation of stem cell populations into cells of the neural lineage, including adult NSCs. Retinoids, which include vitamin A (retinol) and 
its subtypes, are critical contributors to the development of organs in the vertebrate central nervous system, particularly the spinal cord $(50,51)$.

The analysis of Tubb3 and $M b p$ expression indicated that the medium containing noggin and FGF8 promoted the induction of neural cell differentiation in mGSCs. Noggin, a signaling protein, plays an important role in promoting somite patterning in the developing embryo (52). Released from the notochord, noggin regulates BMP during development and blocks BMP4 signaling (53), which results in neural differentiation patterning in the developing embryo. Additionally, in Xenopus, BMP4 inhibition induces the neural differentiation of the ectoderm (54). In the present study, treatment with BMP4 (5 ng/ml) decreased CD24 expression and downregulated neural-related gene expression.

In conclusion, the findings of this study demonstrate that CD24 expression, enhanced by a combination of RA, noggin and FGF8 under serum-free conditions, promotes the differentiation of cells into neural cell precursors. Using a simple cell-sorting method, we obtained neural precursor cells from differentiated mGSCs with the potential to differentiate into mature neurons and astrocytes in vitro. The use of mGSCs avoids the ethical quandaries surrounding embryo destruction. Furthermore, with the use of mGSCs, the opportunity for autotransplantation would circumvent immunological problems. The neural differentiation potential of $\mathrm{CD} 24^{+}$cells derived from ESCs, iPSCs and mGSCs was similar. A CD24-based neural precursor marker system using mGSCs derived from the adult testis may be a preferred strategy for future therapeutic applications. In addition, it has the advantage of providing cells that are genetically matched to their donor without the introduction of reprogramming transcription factors.

\section{Acknowledgments}

The present study was supported by the Next-Generation BioGreen 21 Program (no. PJ011347) and the Excellent Student Scholarship 2015 from Chung-Ang University, Republic of Korea.

\section{References}

1. Hu BY, Du ZW, Li XJ, Ayala M and Zhang SC: Human oligodendrocytes from embryonic stem cells: Conserved SHH signaling networks and divergent FGF effects. Development 136: $1443-1452,2009$

2. Li XJ, Du ZW, Zarnowska ED, Pankratz M, Hansen LO, Pearce RA and Zhang SC: Specification of motoneurons from human embryonic stem cells. Nat Biotechnol 23: 215-221, 2005.

3. Perrier AL, Tabar V, Barberi T, Rubio ME, Bruses J, Topf N, Harrison NL and Studer L: Derivation of midbrain dopamine neurons from human embryonic stem cells. Proc Natl Acad Sci USA 101: 12543-12548, 2004.

4. Roy NS, Cleren C, Singh SK, Yang L, Beal MF and Goldman SA: Functional engraftment of human ES cell-derived dopaminergic neurons enriched by coculture with telomerase-immortalized midbrain astrocytes. Nat Med 12: 1259-1268, 2006.

5. Watanabe K, Ueno M, Kamiya D, Nishiyama A, Matsumura M, Wataya T, Takahashi JB, Nishikawa S, Nishikawa S, Muguruma K and Sasai Y: A ROCK inhibitor permits survival of dissociated human embryonic stem cells. Nat Biotechnol 25: 681-686, 2007.

6. Yang L, Soonpaa MH, Adler ED, Roepke TK, Kattman SJ, Kennedy M, Henckaerts E, Bonham K, Abbott GW, Linden RM, et al: Human cardiovascular progenitor cells develop from a $\mathrm{KDR}^{+}$embryonic-stem-cell-derived population. Nature 453: 524-528, 2008.
7. Nishikawa S, Goldstein RA and Nierras CR: The promise of human induced pluripotent stem cells for research and therapy. Nat Rev Mol Cell Biol 9: 725-729, 2008.

8. Takahashi K and Yamanaka S: Induction of pluripotent stem cells from mouse embryonic and adult fibroblast cultures by defined factors. Cell 126: 663-676, 2006.

9. Spradling A, Drummond-Barbosa D and Kai T: Stem cells find their niche. Nature 414: 98-104, 2001.

10. Conrad S, Renninger M, Hennenlotter J, Wiesner T, Just L, Bonin M, Aicher W, Bühring HJ, Mattheus U, Mack A, et al: Generation of pluripotent stem cells from adult human testis. Nature 456: 344-349, 2008.

11. Guan K, Nayernia K, Maier LS, Wagner S, Dressel R, Lee JH, Nolte J, Wolf F, Li M, Engel W and Hasenfuss G: Pluripotency of spermatogonial stem cells from adult mouse testis. Nature 440: 1199-1203, 2006

12. Izadyar F, Pau F, Marh J, Slepko N, Wang T, Gonzalez R, Ramos T, Howerton K, Sayre C and Silva F: Generation of multipotent cell lines from a distinct population of male germ line stem cells. Reproduction 135: 771-784, 2008.

13. Kanatsu-Shinohara M, Inoue K, Lee J, Yoshimoto M, Ogonuki N, Miki H, Baba S, Kato T, Kazuki Y, Toyokuni S, et al: Generation of pluripotent stem cells from neonatal mouse testis. Cell 119: 1001-1012, 2004

14. Kanatsu-Shinohara M, Lee J, Inoue K, Ogonuki N, Miki H, Toyokuni S, Ikawa M, Nakamura T, Ogura A and Shinohara T: Pluripotency of a single spermatogonial stem cell in mice. Biol Reprod 78: 681-687, 2008.

15. Ko K, Tapia N, Wu G, Kim JB, Bravo MJ, Sasse P, Glaser T, Ruau D, Han DW, Greber B, et al: Induction of pluripotency in adult unipotent germline stem cells. Cell Stem Cell 5: 87-96, 2009.

16. Seandel M, James D, Shmelkov SV, Falciatori I, Kim J, Chaval S Scherr DS, Zhang F, Torres R, Gale NW, et al: Generation of functional multipotent adult stem cells from GPR $125^{+}$germline progenitors. Nature 449: 346-350, 2007.

17. Kim BJ, Lee YA, Kim YH, Kim KJ, Jung MS, Ha SJ, Kang HG, Kim BG, Do JT, Yang HS and Ryu BY: Establishment of adult mouse testis-derived multipotent germ line stem cells and comparison of lineage-specific differentiation potential. Tissue Eng Regen Med 11: 121-130, 2014.

18. Glaser T, Opitz T, Kischlat T, Konang R, Sasse P, Fleischmann BK, Engel W, Nayernia K and Brüstle O: Adult germ line stem cells as a source of functional neurons and glia. Stem Cells 26: 2434-2443, 2008.

19. Baumgarth $\mathrm{N}$ and Roederer $\mathrm{M}$ : A practical approach to multicolor flow cytometry for immunophenotyping. J Immunol Methods 243: 77-97, 2000.

20. Kantor AB and Roederer M: FACS analysis of leukocytes. In: Handbook of Experimental Immunology. Herzenberg LA, Weir DM and Blackwell C (eds). Blackwell Science, Boston, pp43-49, 1996.

21. Morrison SJ, Uchida N and Weissman IL: The biology of hematopoietic stem cells. Annu Rev Cell Dev Biol 11: 35-71, 1995.

22. Zola $\mathrm{H}$ : Medical applications of leukocyte surface molecules-the CD molecules. Mol Med 12: 312-316, 2006.

23. Iversen SD and Iversen LL: Dopamine: 50 years in perspective. Trends Neurosci 30: 188-193, 2007.

24. Fraichard A, Chassande O, Bilbaut G, Dehay C, Savatier P and Samarut J: In vitro differentiation of embryonic stem cells into glial cells and functional neurons. J Cell Sci 108: 3181-3188, 1995.

25. Megiorni F, Mora B, Indovina $P$ and Mazzilli MC: Expression of neuronal markers during NTera2/cloneD1 differentiation by cell aggregation method. Neurosci Lett 373: 105-109, 2005.

26. Caceres A, Mautino J and Kosik KS: Suppression of MAP2 in cultured cerebellar macroneurons inhibits minor neurite formation. Neuron 9: 607-618, 1992.

27. Dehmelt L, Smart FM, Ozer RS and Halpain S: The role of microtubule-associated protein $2 \mathrm{c}$ in the reorganization of microtubules and lamellipodia during neurite initiation. J Neurosci 23: 9479-9490, 2003.

28. Harada A, Teng J, Takei Y, Oguchi K and Hirokawa N: MAP2 is required for dendrite elongation, PKA anchoring in dendrites, and proper PKA signal transduction. J Cell Biol 158: 541-549, 2002.

29. Tesar PJ, Chenoweth JG, Brook FA, Davies TJ, Evans EP, Mack DL, Gardner RL and McKay RD: New cell lines from mouse epiblast share defining features with human embryonic stem cells. Nature 448: 196-199, 2007. 
30. Zhang SC: Defining glial cells during CNS development. Nat Rev Neurosci 2: 840-843, 2001.

31. Bouhon IA, Kato H, Chandran S and Allen ND: Neural differentiation of mouse embryonic stem cells in chemically defined medium. Brain Res Bull 68: 62-75, 2005.

32. Finley MF, Devata S and Huettner JE: BMP-4 inhibits neural differentiation of murine embryonic stem cells. J Neurobiol 40: 271-287, 1999.

33. Okabe S, Forsberg-Nilsson K, Spiro AC, Segal M and McKay RD Development of neuronal precursor cells and functional postmitotic neurons from embryonic stem cells in vitro. Mech Dev 59: 89-102, 1996.

34. Tropepe V, Hitoshi S, Sirard C, Mak TW, Rossant J and van der Kooy D: Direct neural fate specification from embryonic stem cells: A primitive mammalian neural stem cell stage acquired through a default mechanism. Neuron 30: 65-78, 2001.

35. Watanabe K, Kamiya D, Nishiyama A, Katayama T, Nozaki S, Kawasaki H, Watanabe Y, Mizuseki K and Sasai Y: Directed differentiation of telencephalic precursors from embryonic stem cells. Nat Neurosci 8: 288-296, 2005.

36. Wiles MV and Johansson BM: Embryonic stem cell development in a chemically defined medium. Exp Cell Res 247: 241-248, 1999.

37. Ying QL, Stavridis M, Griffiths D, Li M and Smith A: Conversion of embryonic stem cells into neuroectodermal precursors in adherent monoculture. Nat Biotechnol 21: 183-186, 2003.

38. Kawasaki H, Mizuseki K, Nishikawa S, Kaneko S, Kuwana Y, Nakanishi S, Nishikawa SI and Sasai Y: Induction of midbrain dopaminergic neurons from ES cells by stromal cell-derived inducing activity. Neuron 28: 31-40, 2000.

39. Lee SH, Lumelsky N, Studer L, Auerbach JM and McKay RD: Efficient generation of midbrain and hindbrain neurons from mouse embryonic stem cells. Nat Biotechnol 18: 675-679, 2000.

40. Wichterle H, Lieberam I, Porter JA and Jessell TM: Directed differentiation of embryonic stem cells into motor neurons. Cell 110: 385-397, 2002.

41. Cai $C$ and Grabel L: Directing the differentiation of embryonic stem cells to neural stem cells. Dev Dyn 236: 3255-3266, 2007.

42. Kay R, Rosten PM and Humphries RK: CD24, a signal transducer modulating $\mathrm{B}$ cell activation responses, is a very short peptide with a glycosyl phosphatidylinositol membrane anchor. J Immunol 147: 1412-1416, 1991.

43. Williams LA, McLellan AD, Summers KL, Sorg RV Fearnley DB and Hart DN: Identification of a novel dendritic cell surface antigen defined by carbohydrate specific CD24 antibody cross-reactivity. Immunology 89: 120-125, 1996.
44. Calaora V, Chazal G, Nielsen PJ, Rougon G and Moreau H: $\mathrm{mCD} 24$ expression in the developing mouse brain and in zones of secondary neurogenesis in the adult. Neuroscience 73: 581-594, 1996.

45. Axell MZ,Zlateva S and Curtis M: A method for rapid derivation and propagation of neural progenitors from human embryonic stem cells. J Neurosci Methods 184: 275-284, 2009.

46. Do JT, Joo JY, Han DW, Araúzo-Bravo MJ, Kim MJ, Greber B, Zaehres H, Sobek-Klocke I, Chung HM and Schöler HR: Generation of parthenogenetic induced pluripotent stem cells from parthenogenetic neural stem cells. Stem Cells 27: 2962-2968, 2009.

47. Gerrard L, Rodgers L and Cui W: Differentiation of human embryonic stem cells to neural lineages in adherent culture by blocking bone morphogenetic protein signaling. Stem Cells 23: 1234-1241, 2005.

48. Hicks AU, Lappalainen RS, Narkilahti S, Suuronen R, Corbett D, Sivenius J, Hovatta $\mathrm{O}$ and Jolkkonen J: Transplantation of human embryonic stem cell-derived neural precursor cells and enriched environment after cortical stroke in rats: Cell survival and functional recovery. Eur J Neurosci 29: 562-574, 2009.

49. Koch P, Opitz T, Steinbeck JA, Ladewig J and Brüstle O: A rosette-type, self-renewing human ES cell-derived neural stem cell with potential for in vitro instruction and synaptic integration. Proc Natl Acad Sci USA 106: 3225-3230, 2009.

50. Maden M: Retinoid signalling in the development of the central nervous system. Nat Rev Neurosci 3: 843-853, 2002.

51. Pierani A, Brenner-Morton S, Chiang C and Jessell TM: A sonic hedgehog-independent, retinoid-activated pathway of neurogenesis in the ventral spinal cord. Cell 97: 903-915, 1999.

52. Hirsinger E, Duprez D, Jouve C, Malapert P, Cooke J and Pourquié O: Noggin acts downstream of Wnt and Sonic Hedgehog to antagonize BMP4 in avian somite patterning. Development 124: 4605-4614, 1997.

53. Marcelino J, Sciortino CM, Romero MF, Ulatowski LM, Ballock RT, Economides AN, Eimon PM, Harland RM and Warman ML: Human disease-causing NOG missense mutations: Effects on noggin secretion, dimer formation, and bone morphogenetic protein binding. Proc Natl Acad Sci USA 98: 11353-11358, 2001.

54. Sasai Y, Lu B, Steinbeisser H and De Robertis EM: Regulation of neural induction by the Chd and Bmp-4 antagonistic patterning signals in Xenopus. Nature 376: 333-336, 1995. 